\title{
Laparoscopic Rectovaginal Septal Repair without Mesh for Anterior Rectocele
}

\author{
Han Deok Kwak, M.D., Ph.D., Jae Kyun Ju, M.D., Ph.D. \\ Department of Surgery, Chonnam National University Hospital, Gwangju, Korea
}

\begin{abstract}
A rectocele with a weakened rectovaginal septum can be repaired with various surgical techniques. We performed laparoscopic posterior vaginal wall repair and rectovaginal septal reinforcement without mesh using a modified transperineal approach. A 63-year-old woman with outlet dysfunction constipation complained of lower pelvic pressure and sense of heaviness for 30 years. Initial defecography showed an anterior rectocele with a 45- $\mathrm{mm}$ anterior bulge and perineal descent. Laparoscopic procedures included peritoneal and rectovaginal septal dissection directed toward the perineal body, rectovaginal septal suturing, and peritoneal closure. The patient started a soft diet the following day and was discharged on the 5th postoperative day without any complications. The patient had no dyschezia or dyspareunia, and no problem with bowel function; 3-month follow-up defecography showed a decrease in bulging to $18 \mathrm{~mm}$. Laparoscopic posterior vaginal wall and rectovaginal septal repair is safe and feasible for treatment of a rectocele, and enables early recovery.
\end{abstract}

Keywords: Laparoscopy, Rectocele, Posterior vaginal wall, Rectovaginal septum
Received February 26, 2018

Revised April 17, 2018

Accepted May 16, 2018

Corresponding author

Jae Kyun Ju

Department of Surgery, Chonnam

National University Hospital, 42

Jaebong-ro, Dong-gu, Gwangju

61469, Korea

Tel: +82-62-227-1635

Fax: +82-62-220-6456

E-mail: jkju@chonnam.ac.kr ORCID:

http://orcid.org/0000-0003-1605-3310

Copyright @ 2018 The Journal of Minimally Invasive Surgery. All rights reserved.

This is an Open Access article distributed under the terms of the Creative Commons Attribution Non-Commercial License (http:// creativecommons.org/licenses/by-nc/4.0/) which permits unrestricted non-commercial use, distribution, and reproduction in any medium, provided the original work is properly cited.

\section{INTRODUCTION}

Although rectocele was first described by Garengeot in 1736, it was not until 1970 that the definition of the rectovaginal septum, which is a fascia analogous to Denonvilliers' fascia in males, was reported. ${ }^{1}$ Rectocele is caused by a weakened rectovaginal septum; however, whether a true rectovaginal septum exists is still debated. What is apparent is that fibromuscular tissue exists clearly between the vaginal mucosa and the rectal wall. ${ }^{2}$ DeLancey ${ }^{3}$ divides rectocele into three levels according to position; in particular, the middle third (level II) was reportedly related to a rectovaginal fascia. Patients with rectocele typically complain of obstructed defecation, a perineal bulge, and incomplete emptying, which is shown as an outpouching of the rectum into the vagina during the evacuation process on imaging.

\section{CASE REPORT}

A 63-year-old para 3 woman presented to the outpatient clinic with a complaint of incomplete emptying and constipation requiring digital splinting. She also had a sensation of lower pelvic pressure and heaviness for 30 years. On defecography, a 45- $\mathrm{mm}$ anterior rectocele with perineal descent, comparable to level II in the DeLancey classification, was noted (Fig. 1A).

Prior to surgery, bowel preparation was not performed, and a prophylactic intravenous second-generation cephalosporin was administered just before surgery. The patient was placed in lithotomy position for vaginal and rectal examination during surgery. A 12-mm trocar was positioned at the umbilical area for a camera, and four 5-mm trocars were inserted into the right and left upper and lower quadrants, respectively. 

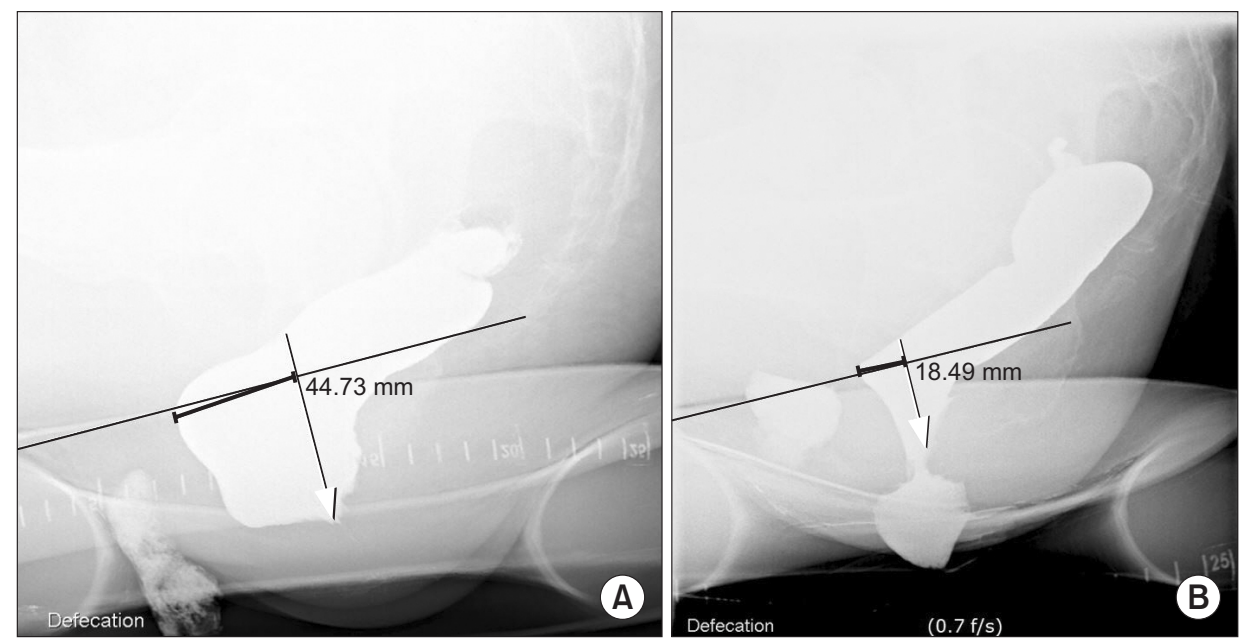

Fig. 1. Three-month postoperative defecography (B) shows decreased bulging (thick black line) compared with that before surgery (A). White line, pubococcygeal line.
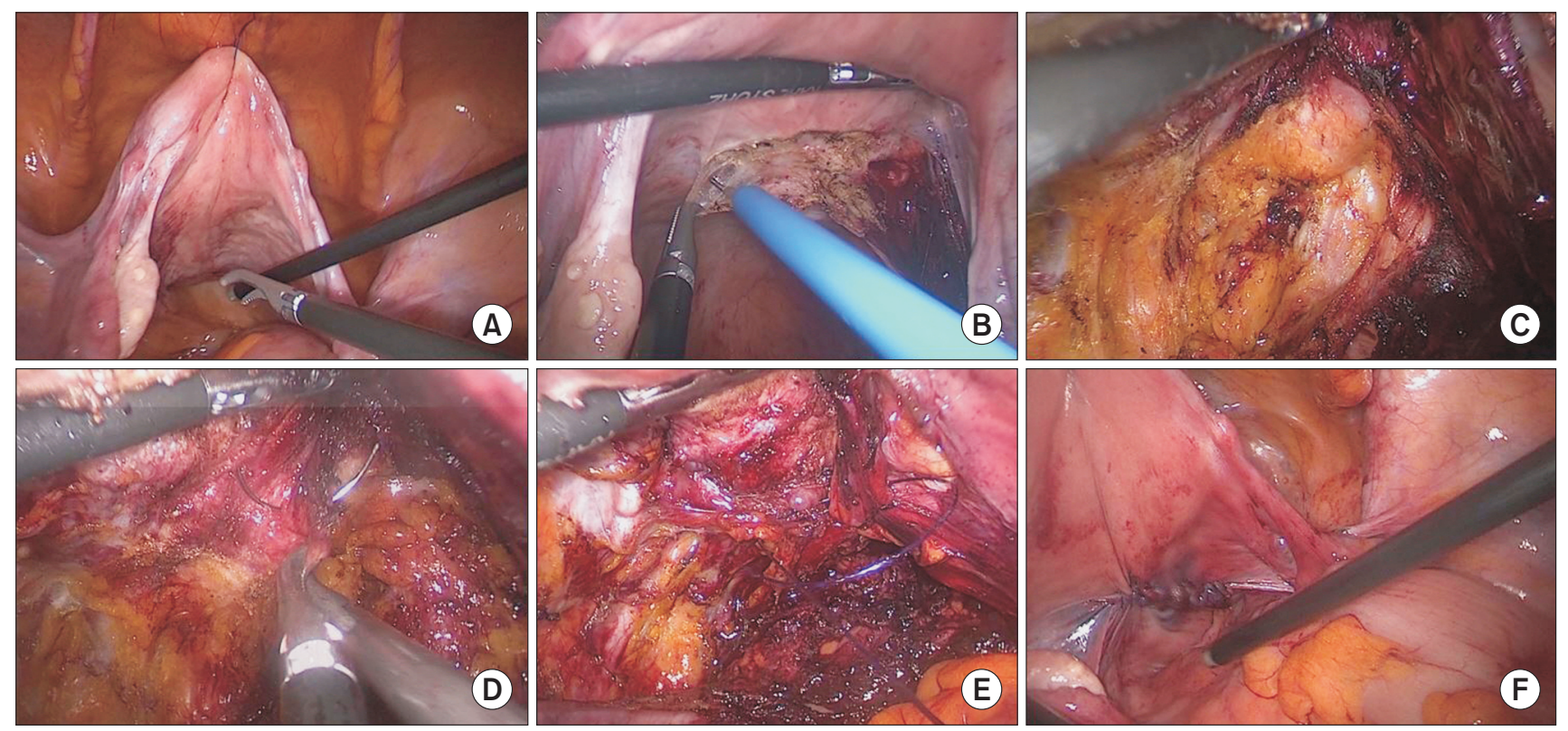

Fig. 2. Laparoscopic posterior vaginal wall repair and rectovaginal septal reinforcement for rectocele: (A) Fixation of uterus, (B) Peritoneal dissection, (C) Rectovaginal septal dissection and palpation, (D) Suture at rectovaginal excavation, (E) Reinforcement of rectovaginal septum, (F) Peritoneal closure.

The small intestine was shifted upward with Trendelenburg positioning. Before peritoneal dissection, the fundus of the uterus was fixed to the abdominal peritoneum using 1-0 Prolene with a linear needle (Fig. 2A). Dissection started from the peritoneal reflection between the posterior vaginal wall and serosa of the rectum, and was directed toward the perineal body with the guidance of vaginal and digital rectal examination (Fig. 2B, C). As noted, the rectovaginal septum consists of fibromuscular tissue, with a more firmly adherent and densely membranous attachment to the vagina, and a relatively loose connective tissue attachment to the rectal wall. Therefore, to avoid injury, the septum was dissected adjacent to the rectum. In addition, the neurovascular bundle of Walsh and the inferior hypogastric plexus are located posterolateral to the vagina. ${ }^{4}$ These require meticulous dissection as well as accurate identification of anatomical structures. Once the urogenital diaphragm was verified, continuous suturing of the rectovaginal septum and posterior vaginal wall started from the distal end of the dissection (Fig. 2D). Then, the suture line was reinforced with 3-0 Vicryl (Fig. 2E). The repair finished with peritoneal closure (Fig. 2F). Blood loss was minimal, and the author did not use a drain. The time from skin incision to closure of the trocar sites was around 90 minutes.

The patient started a diet on the day after surgery, and was 
discharged on the 5th postoperative day without complications. She had no dyschezia or dyspareunia, and no problem with bowel habits at 1- and 3-month outpatient follow-up. Defecography was performed 3 months after the operation. The anterior rectocele decreased to $18 \mathrm{~mm}$ (Fig. 1B).

\section{DISCUSSION}

We present a successful laparoscopic repair without mesh for anterior rectocele. Although surgery with spinal anesthesia is less invasive than laparoscopic surgery requiring general anesthesia, minimally invasive surgery provides improved visualization, effective hemostasis, and shortened hospitalization. Of course, it may be safe to perform a surgical procedure under spinal anesthesia with a transvaginal, transanal, or transperineal approach in elderly patients or those with significant medical comorbidities. Laparoscopic correction may be preferred, however, given that it enables safe use of general anesthesia, and reduces the risk of cord injury when a patient had spinal surgery or spinal cord disease. Potential complications caused by mesh are also not of concern with this procedure. Therefore, our method may provide preliminary data for an ongoing study comparing other surgical methods with laparoscopic surgery.

Rectocele repair can be performed with various surgical techniques. Repair can be classified as transvaginal, transanal, transperineal, or abdominal, according to the incisional approach the gynecologist or proctologist is most familiar with. ${ }^{2}$ Different approaches also include a wide variety of surgical procedures, with simple suturing, colporrhaphy, plication, abdominal suspension, etc. A prospective randomized study compared 15 transanal rectoceleplasty and 15 vaginal posterior colporrhaphy procedures, and the transanal technique was associated with higher recurrence rates (40\%) than with use of the transvaginal approach $(7 \%)(p=0.04))^{5}$ A Cochrane systematic review reported that posterior vaginal wall repair may have lower risk of recurrence compared with transanal repair. ${ }^{6}$ Another randomized controlled trial showed that transperineal repair is superior to the transanal approach in structural and functional outcomes.

The debate over whether to use mesh has persisted until recently. A study of 18 patients reported that mesh was effective in correction of rectocele and produced an improved functional outcome, ${ }^{8}$ while a randomized study showed no improvement in anatomical results. ${ }^{9}$ It has been reported that additional surgery may be required due to erosion of permanent mesh. ${ }^{6}$ Use of native tissue was less likely to require cystotomy compared to use of any other type of mesh, resulting in less bladder damage. ${ }^{10}$ The clinical benefits of non-mesh surgery include decreased operative time, less blood loss, low rate of apical or posterior compartment prolapse, and less de novo stress-free urinary incontinence. Although newer, lighterweight, and single-incision mesh products are under evaluation in several trials, usable mesh products such as absorbable biological grafts or polypropylene mesh do not have a clear advantage over native tissue. Therefore, a recent Cochrane review concluded that current evidence does not support the use of mesh compared with use of native tissue repair for anterior rectocele owing to increased morbidity. ${ }^{10}$

In conclusion, laparoscopic rectovaginal septal repair without mesh is a safe and feasible technique for the management of anterior rectocele.

\section{REFERENCES}

1) Nichols DH, Milley PS. Surgical significance of the rectovaginal septum. Am J Obstet Gynecol 1970;108:215-220.

2) Mustain WC. Functional Disorders: Rectocele. Clin Colon Rectal Surg 2017;30:63-75.

3) DeLancey JO. Structural anatomy of the posterior pelvic compartment as it relates to rectocele. Am J Obstet Gynecol 1999;180:815823.

4) Acar HI, Kuzu MA. Important points for protection of the autonomic nerves during total mesorectal excision. Dis Colon Rectum 2012;55:907-912.

5) Nieminen K, Hiltunen KM, Laitinen J, Oksala J, Heinonen PK. Transanal or vaginal approach to rectocele repair: a prospective, randomized pilot study. Dis Colon Rectum 2004;47:1636-1642.

6) Maher C, Baessler K, Glazener CM, Adams EJ, Hagen S. Surgical management of pelvic organ prolapse in women. Cochrane Database Syst Rev 2007:Cd004014.

7) Farid M, Madbouly KM, Hussein A, Mahdy T, Moneim HA, Omar W. Randomized controlled trial between perineal and anal repairs of rectocele in obstructed defecation. World J Surg 2010;34:822829.

8) D’Hoore A, Vanbeckevoort D, Penninckx F. Clinical, physiological and radiological assessment of rectovaginal septum reinforcement with mesh for complex rectocele. Br J Surg 2008;95:1264-1272.

9) Paraiso MF, Barber MD, Muir TW, Walters MD. Rectocele repair: a randomized trial of three surgical techniques including graft augmentation. Am J Obstet Gynecol 2006;195:1762-1771.

10) Maher C, Feiner B, Baessler K, Christmann-Schmid C, Haya N, Brown J. Surgery for women with anterior compartment prolapse. Cochrane Database Syst Rev 2016;11:Cd004014. 